\title{
PROCESSO DE PRIORIZAÇÃO DE OCORRÊNCIAS NO SERVIÇO DE ATENDIMENTO MÓVEL DE URGÊNCIA
}

\author{
PROCESS OF PRIORIZATION OF OCCURRENCES IN \\ THE MOBILE EMERGENCY SERVICE
}

\section{PROCESSO DE PRIORIZACIÓN DE OCURRENCIAS EN EL SERVICIO DE ATENCIÓN MÓVIL DE URGENCIAS}

\author{
Flavia Saraiva Leão Fernandes ${ }^{1}$ \\ Oswaldo Yoshimi Tanaka
}

Como citar este artigo: Fernandes FSL, Tanaka OY. Processo de priorização de ocorrências no serviço de atendimento móvel de urgência. Rev baiana enferm. 32:e24463.

\begin{abstract}
Objetivo: identificar características das ocorrências priorizadas pela Central de Regulação do Serviço de Atendimento Móvel de Urgência de uma grande metrópole e compreender quais fatores influenciam os médicos reguladores no processo de priorização de despacho de ambulância. Método: estudo retrospectivo com métodos mistos, entre 2012 e 2014. As variáveis despacho e tempo de regulação foram investigadas. As entrevistas realizadas foram submetidas à análise de conteúdo. Resultados: a demanda é majoritariamente clínica, classificada com Determinantes de alta prioridade e prioritariamente dos serviços de segurança pública. O tempo resposta é inversamente proporcional à prioridade. Médicos priorizam casos com: risco de morte; deterioração clínica; necessidade de transporte; vulnerabilidade associada à idade e violência. Conclusão: condições clínicas, vulnerabilidade e risco determinam o tipo de atendimentos e o tempo de resposta. Diante de um cenário de poucos recursos, a atuação dos médicos reguladores no processo de priorização visa adequar a demanda à oferta disponível.
\end{abstract}

Descritores: Centro de operações de emergência. Emergências. Serviços médicos de emergência. Ambulâncias.

Objective: identify characteristics of the events prioritized by the Regulation Office of the Mobile Emergency Care Service in a major city and understand which factors influence the regulating physicians in the ambulance dispatch prioritization process. Method: retrospective study with a mixed-methods design, undertaken between 2012 and 2014. The variables dispatch and regulation time were investigated. The interviews held were submitted to content analysis. Results: the nature of the demand is mainly clinical, classified with bigh-priority determinants, mainly from public safety services. The response time is inversely proportional to the priority. Physicians prioritize cases with: risk of death; clinical deterioration; need for transport; vulnerability associated with age and violence. Conclusion: clinical conditions, vulnerability and risk determine the type of care and the response time. In a scenario of few resources, the regulating physicians' activities in the prioritization process is intended to adapt the demand to the available supply.

Descriptors: Emergency operations Center. Emergencies. Emergency medical services. Ambulances.

Objetivo: identificar características de las ocurrencias priorizadas por el Centro Regulador del Servicio de Atención Móvil de Urgencias de una gran metrópolis y comprender cuales factores influyen en los médicos reguladores en el proceso de priorización de despacho de ambulancia. Método: estudio retrospectivo con métodos mistos, entre 2012 y 2014. Las variables despacho y tiempo de regulación fueron investigadas. Las entrevistas realizadas fueron

Enfermeira. Doutora em Saúde Pública. Mestre em Saúde Coletiva. São Paulo, SP, Brasil. flaviaslf@gmail.com

Médico. Doutor em Saúde Pública. Livre Docência e Professor Titular do Departamento de Política, Gestão e Saúde da Faculdade de Saúde Pública da Universidade de São Paulo. Coordenador do Grupo Temático de Monitoramento e Avaliação de Programas, Serviços, Sistemas e Políticas de Saúde da Abrasco. Diretor da Faculdade de Saúde Pública de São Paulo. São Paulo, SP, Brasil. 
sometidas al análisis de contenido. Resultados: la demanda es principalmente clínica, clasificada con Determinantes de alta prioridad y prioritariamente de los servicios de seguridad pública. El tiempo de respuesta es inversamente proporcional a la prioridad. Médicos priorizan casos con: riesgo de muerte; deterioro clínico; necesidad de trasporte; vulnerabilidad asociada al edad y violencia. Conclusión: condiciones clínicas, vulnerabilidad y riesgo determinan el tipo de atención y el tiempo de respuesta. Ante un escenario de pocos recursos, la actuación de los médicos reguladores en el proceso de priorización visa adecuar la demanda a la oferta disponible.

Descriptores: Centro de operaciones de emergencia. Urgencias médicas. Servicios médicos de urgencia. Ambulancias.

\section{Introdução}

$\mathrm{O}$ atendimento pré-hospitalar (APH) teve início no contexto militar, quando soldados iniciavam o tratamento dos feridos no campo de batalha e os transportavam ao hospital. Desde então, diversas iniciativas surgiram para transferir os conhecimentos adquiridos para a população civil, predominantemente relacionados ao trauma. Em 1960, o escopo da atuação do APH expandiu, com a inclusão da assistência a agravos clínicos, devido a avanços tecnológicos na assistência a morte súbita ${ }^{(1)}$.

No Brasil, o Corpo de Bombeiros foi, por um longo período, o APH predominante no país, com tímida participação do setor saúde. Um esforço conjunto entre saúde e segurança pública ocorreu em São Paulo, com o Projeto Resgate, em 1989. Este modelo, envolvendo duas secretarias, foi proposto em 1990 pelo Ministério da Saúde com o Serviço Integrado de Atendimento ao Trauma em Emergência (SIATE), implantado inicialmente em Curitiba e, em 1995, em Belo Horizonte $^{(2)}$.

A partir da década de 1990, mediante a Cooperação Técnica e Científica Franco-Brasileira, municípios implantaram APH centrados no médico regulador, com participação da enfermagem na assistência, no âmbito das secretarias de saúde. O desenvolvimento do APH ficou atrelado à saúde, com a criação, em 2002, do Serviço de Atendimento Móvel de Urgência (SAMU 192) no âmbito do Sistema Único de Saúde (SUS) e no contexto da Norma Operacional da Assistência à Saúde (NOAS) 1/2002 $2^{(3)}$.

A Política Nacional de Atenção às Urgências (PNAU), publicada em 2003, tornou o SAMU prioridade do governo federal, tendo em vista seu potencial de ser organizador do fluxo de atenção às urgências, conformando-se como uma porta de entrada e, ao receber as demandas da população, ser um observatório, evidenciando as deficiências da rede e subsidiando ações de planejamento ${ }^{(4)}$. Estudo realizado em Ribeirão Preto (SP) demonstrou que a implantação do SAMU melhorou o acesso de paciente grave a referência hospitalar terciária e diminuiu a demanda de baixa complexidade do hospital ${ }^{(5)}$.

A implantação do SAMU variou entre os es$\operatorname{tados}^{(6)}$, inclusive no que tange à integração com o Corpo de Bombeiros ${ }^{(6-7)}$. Apesar do crescente financiamento federal, a falta de estruturação da rede de atenção e o atraso na descentralização dos recursos federais reproduzem desigualdades regionais e sobrecarregam as gestões municipais ${ }^{(8)}$. Fragilidades relacionadas à capacidade de gestão colegiada, à estrutura e à falta de material em ambulâncias, por entraves burocráticos, além de fragilidade política na gestão do trabalho, foram encontradas numa pesquisa avaliativa realizada em Santa Catarina ${ }^{(9)}$.

A maioria dos estudos publicados em relação ao SAMU diz respeito ao perfil da demanda. As urgências clínicas compõem a maioria dos atendimentos em diversas regiões, variando entre $50,2 \%$ a $77,2 \%$ do total de ocorrências ${ }^{(10-14)}$. Os acidentes de trânsito correspondem à maioria das ocorrências relacionadas às causas externas, variando de 53,5\% em Teresina (PI) a 86,6\% em Olinda $(\mathrm{PE})^{(10,12,15-16)}$. Dentre os estudos levantados, apenas duas pesquisas apresentaram dados em relação à gravidade das ocorrências. Em Catanduva (SP), os pesquisadores realizaram a classificação das ocorrências atendidas pelas 
unidades básicas e avançadas do SAMU pelo método Simple Triage and Rapid Treatment (START) e constataram que $2,1 \%$ dos atendimentos eram graves, $28,1 \%$ moderados e $69,6 \%$ leves $^{(14)}$.

Outro estudo, que apresentou dados em relação à gravidade presumida, foi uma tese de doutorado. Realizado no SAMU de Porto Alegre (RS), identificou que $79,6 \%$ das ocorrências que receberam despacho de ambulância foram avaliadas como gravidade média, 3,0\% severa e $14,1 \%$ gravidade pequena ${ }^{(17)}$. Entretanto, a comparação entre os SAMU é prejudicada pela falta de instrumento de captação de dados em âmbito nacional ${ }^{(9-10)}$.

O SAMU configurou-se como uma porta de entrada ao SUS e, após mais de uma década de implantação, torna-se importante lançar um olhar crítico a esse serviço, a fim de identificar os potenciais propostos na PNAU. A investigação sobre o processo de trabalho das Centrais de Regulação permitiria compreender como o SAMU conforma-se como porta de entrada à Rede de Atenção às Urgências (RAU).

O objetivo deste estudo foi identificar características das ocorrências priorizadas pela Central de Regulação do SAMU de uma grande metrópole e compreender quais fatores influenciam os médicos reguladores no processo de priorização de despacho de ambulância.

\section{Método}

Trata-se de um estudo retrospectivo, realizado entre 2012 e 2014, envolvendo a estratégia de métodos mistos, de forma integrada e sequencial à abordagem quantitativa e qualitativa ${ }^{(18)}$. Esta estratégia foi escolhida, a fim de identificar/buscar corroboração na análise dos diferentes tipos de dados ${ }^{(19)}$.

O estudo foi realizado no SAMU do município de São Paulo (SAMU SP), Brasil, que tem administração municipal, oferece $100 \%$ de cobertura a mais de 11 milhões de habitantes e atua de forma complementar ao Corpo de Bombeiros.

O processo de priorização inicia com os atendentes de telefonia que operam o Medical Priority Dispatch System ${ }^{T M}\left(\right.$ MPDS $^{\circledR}$ Salt Lake City,
UT, Versão 12.1), um sistema informatizado de despacho. Uma queixa principal é selecionada no software que, por sua vez, determina o algoritmo com perguntas pré-estabelecidas realizadas pelos atendentes. Ao final do questionário, é atribuído à ocorrência um Determinante de Prioridade: Echo, Delta, Charlie, Bravo, Alfa e Ômega. Estes Determinantes explicitam um gradiente de prioridades, em que Echo representa as ocorrências de maior prioridade, e Ômega as de menor.

A chamada telefônica é encerrada e as informações são transferidas aos médicos reguladores. Estes devem manter a prioridade definida ou alterá-la, e identificar a unidade a ser despachada (suporte básico ou avançado de vida). Após essa decisão, as informações são transferidas para os técnicos auxiliares de regulação médica (TARM) para o despacho de ambulância.

A primeira etapa de coleta de dados foi a observação direta, que permitiu caracterizar o processo de trabalho. Em um segundo momento (segunda etapa) foi construído um banco com dados secundários armazenados na Central de Regulação do SAMU/SP, referentes às ocorrências de outubro de 2012. Estes dados foram disponibilizados à equipe de pesquisa em novembro de 2012, seguido de validação para a construção do banco de dados. Este mês foi escolhido por ser o de maior demanda verificada na série histórica.

Os dados oriundos do referido banco de dados foram submetidos à análise estatística descritiva, que consistiu no cálculo das frequências absolutas e relativas das variáveis categóricas, expressas em porcentagens (dia da semana; plantão; queixa principal; região; Determinante de Prioridade; sexo; despacho de recurso; motivo do encerramento; recurso despachado). Foram calculadas a média, mediana, mínimo, máximo, primeiro e terceiro quartil da variável tempo e idade. A técnica BoxPlots permitiu a visualização das medidas. Foram calculados dois intervalos de tempo: (t0) entre a abertura da ocorrência e o despacho da ambulância (tempo de regulação); e (t1) entre o despacho da ambulância e a chegada ao local da ocorrência (tempo de deslocamento). O tempo resposta é a soma 
desses dois intervalos $(\mathrm{tR}=\mathrm{t} 0+\mathrm{t} 1)$ e consiste no intervalo de tempo decorrido entre a abertura da ocorrência e a chegada ao local da ocorrência.

A terceira etapa consistiu de entrevistas semiestruturadas com médicos reguladores, informantes-chave, após a assinatura do Termo de Consentimento Livre e Esclarecido (TCLE), com a finalidade de descrever qualitativamente os padrões observados na análise descritiva relacionada ao processo de priorização. A identificação dos informantes-chave foi realizada segundo três critérios: extensa experiência como médico regulador; comprometimento com o serviço; experiência prática na assistência pré-hospitalar.

As entrevistas duraram entre 50 minutos a 1 hora e 10 minutos, foram gravadas, transcritas e analisadas pela técnica da análise de conteúdo $^{(20)}$. Para aplicação desta técnica, as seguintes etapas foram seguidas: pré-análise, codificação e tratamento dos resultados, inferência e interpretação.

Os marcadores analíticos que nortearam a leitura das informações das entrevistas buscaram compreender o processo de trabalho do regulador nos seguintes aspectos: administração das chamadas, relação com o protocolo, avaliação telefônica do paciente, processo decisório de priorização das chamadas. Esse procedimento permitiu a identificação das características subjetivas do processo de trabalho e dos fatores que influenciavam os médicos no processo de priorização.

As categorias que emergiram da análise das entrevistas nortearam a quarta etapa, que consistiu de uma segunda análise estatística cuja finalidade foi explicitar quantitativamente os fatores envolvidos na priorização, sendo exploradas a existência ou não de despacho de ambulância e o tempo de regulação (t0) dos seis Determinante de Prioridade.

Cada Determinante foi analisado separadamente, tendo como variável independente as queixas principais mais frequentes (representatividade de no mínimo 10\% do total das ocorrências) e como variáveis independentes o despacho (porcentagem de ocorrências despachadas) e o tempo de regulação (porcentagem de ocorrências com tempo de regulação menor que 10 minutos). Foi utilizado o teste chi quadrado para significância estatística. Considerou-se como significativo o valor de $\mathrm{p}<0,05$.

Essas duas variáveis foram utilizadas como proxy para inferir os critérios de priorização. Maior porcentagem de ocorrências despachadas em menos de 10 minutos indica maior agilidade do SAMU no processo de regulação naquela queixa. A fim de quantificar a dimensão das diferenças, foi calculada a taxa de variação, definida como a porcentagem acima ou abaixo da média total da amostra.

Esta pesquisa foi aprovada pelo Comitê de Ética em Pesquisa da Faculdade de Saúde Pública da Universidade de São Paulo (COEP/447/10).

\section{Resultados}

Em outubro de 2012, a Central de Regulação do SAMU/SP recebeu 202.186 chamados telefônicos. Deste total, 38.211 (18,9\%) foram consideradas ocorrências e classificadas segundo o protocolo. Após a validação do banco, foram excluídas 664 ocorrências (1,7\%), devido à qualidade da variável tempo. Desta forma, 37.457 ocorrências foram incluídas.

As ocorrências clínicas corresponderam a $59,2 \%$ da demanda. As causas externas corresponderam a 26,1\%, sendo Quedas e Acidentes de Trânsito mais frequentes. Apesar de haver baixa completude dos registros de idade e sexo $(42,3 \%)$, constatou-se que a média de idade foi de 50,2 anos (mediana 49), e a proporção de homens e mulheres foi de 52,2\% e 47,8\%, respectivamente.

As proporções dos Determinantes de Prioridade foram: Echo 1,3\%, Delta 50,2\%, Charlie 14,4\%, Bravo 15,5\%, Alfa 18,2\% e Ômega 0,4\%. Nem todas ocorrências completaram as etapas do APH (Figura 1), decrescendo conforme a etapa assistencial avançava no sentido do transporte ao hospital. 
Figura 1 - Evolução da porcentagem de ocorrências segundo etapas do atendimento por Determinante, SAMU SP. Out. $2012(\mathrm{~N}=37.457)$

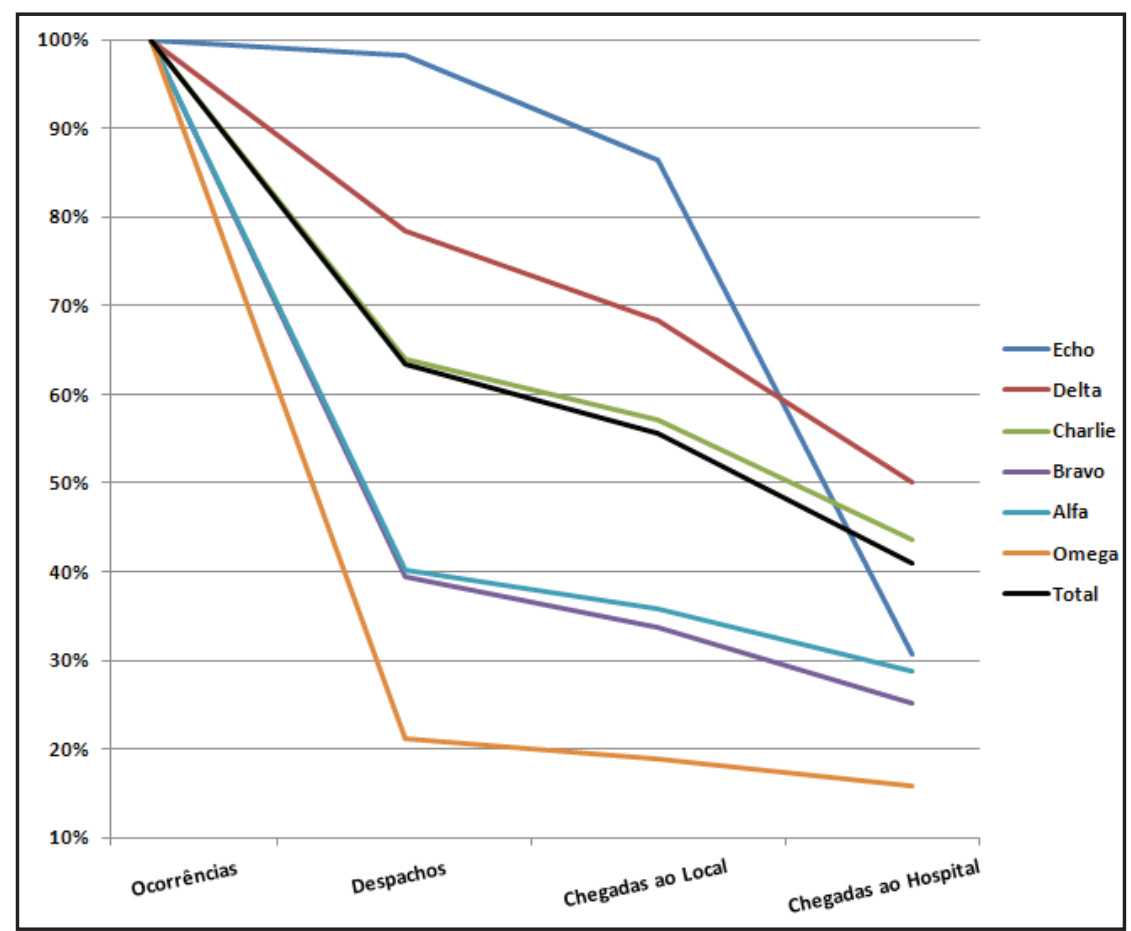

Fonte: Elaboração própria.

A frequência de despacho decresce conforme a prioridade diminui, variando entre $98,1 \%$ (Echo) e 21,2\% (Ômega). Dentre as ocorrências que não receberam o despacho $(36,6 \%), 387$ $(2,8 \%)$ foram consideradas casos não urgentes pelos médicos reguladores; a maioria $(61,4 \%)$ foi cancelada pelos solicitantes, que encontraram outros meios de transporte (polícia, bombeiros ou a própria família). Este dado sugere a crença de que o SAMU não foi ágil o suficiente, segundo os critérios considerados de emergência para a população.
O tempo resposta variou conforme o Determinante, isto é, quanto maior a prioridade, menor o tempo resposta. Não houve diferença nos tempos de deslocamento, indicando que as ambulâncias deslocaram-se de maneira uniforme pela cidade. Identificou-se que o tempo de regulação foi aquele que determinou as diferenças no tempo resposta (Figura 2). A Central de Regulação leva menos tempo para regular e despachar ambulâncias para as ocorrências de maior prioridade. 
Figura 2 - Boxplot t0 das ambulâncias SAMU SP. Out. $2012(\mathrm{~N}=23.736)^{*}$

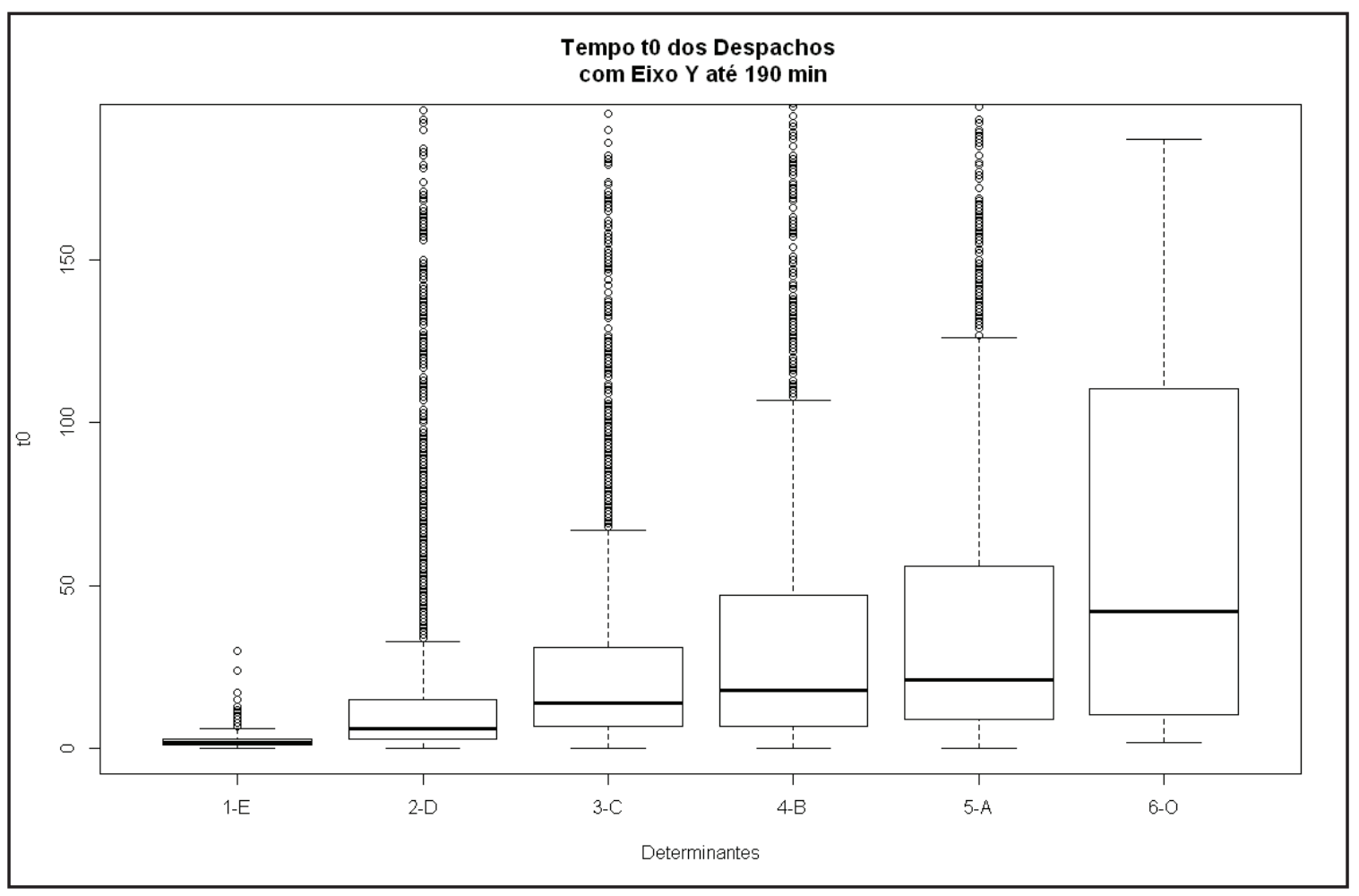

Fonte: Elaboração própria.

*Foi realizado um recorte no eixo Y (em 40 min) para destacar a distribuição dos tempos por determinante até o terceiro quartil. Os outliers não estão representados em sua totalidade na figura.

Na Figura 1, é possível perceber que 98,1\% das ocorrências Echo receberam despacho de ambulância e uma grande parte dessas ambulâncias chegou ao local (86,5\%). Entretanto, apenas uma pequena parcela foi transportada ao hospital (30,8\%). Os códigos de encerramento indicaram que $73,5 \%$ dessas ambulâncias não chegaram ao hospital devido ao óbito do paciente, indicando sua gravidade clínica.

Ao avaliar os tempos de regulação, identifica-se que o terceiro quartil esteve abaixo de 3 minutos. Isto indica que o SAMU SP apresenta agilidade na priorização dos casos Echo, despachando sem avaliação médica. A parada cardiorrespiratória (PCR) correspondeu a 90,3\% das ocorrências Echo e recebeu despacho em 97,9\% dos casos, obtendo mediana de tempo de regulação de 2 minutos.

Segundo o MPDS, os despachos deveriam seguir a ordem estabelecida pela classificação. Devido à restrição do número de ambulâncias, o médico regulador tem a função de avaliar cada ocorrência e realizar o processo de priorização dessas.

A análise das entrevistas possibilitou que emergissem as seguintes categorias relacionadas aos fatores que influenciavam os médicos reguladores no processo de priorização de despacho de ambulância: Condições clínicas reportadas; Condições de riscos específicos; Condições intrínsecas ao SAMU.

\section{Condições clínicas reportadas}

Os médicos reguladores relataram que procuravam sinais e sintomas relatados pelo solicitante que indicassem o risco iminente de morte. Inconsciência e dificuldade respiratória são sinais de alerta para uma possível PCR ou pré-colapso. A Tabela 1 compara as proporções de ocorrências despachadas em menos de 10 minutos entre as três principais queixas nas ocorrências Charlie. É possível identificar que essa proporção foi maior na queixa Inconsciência do que nas demais $(14,9 \%, \mathrm{p}=0,0142)$. 
Tabela 1 - Número e porcentagem de ocorrências Charlie despachados com tempo de regulação acima e abaixo de 10 minutos nas queixas Dor Abdominal, Pessoa Enferma e Inconsciente, SAMU SP. São Paulo, Brasil - out. 2012 ( N=1.399)

\begin{tabular}{|c|c|c|c|c|c|c|c|c|}
\hline \multirow[t]{2}{*}{ Queixa principal } & \multicolumn{2}{|c|}{$\begin{array}{c}\text { TO }<=10 \\
\text { min }\end{array}$} & \multicolumn{2}{|c|}{ TO $>10 \mathrm{~min}$} & \multicolumn{2}{|c|}{ Total } & \multirow{2}{*}{\begin{tabular}{|c|c}
$\begin{array}{c}\text { Taxa de } \\
\text { variação }\end{array}$ \\
$\%$ \\
\end{tabular}} & \multirow[t]{2}{*}{ p-valor } \\
\hline & $\mathbf{n}$ & $\%$ & $\mathbf{n}$ & $\%$ & $\mathbf{n}$ & $\%$ & & \\
\hline $\begin{array}{l}\text { Dor Abdominal/Problemas } \\
\text { Abdominais }\end{array}$ & 182 & 35,7 & 328 & 64,3 & 510 & 36,5 & -6 & 0,0142 \\
\hline $\begin{array}{l}\text { Pessoa Enferma (Diagnóstico } \\
\text { Específico) }\end{array}$ & 161 & 35,2 & 297 & 64,8 & 458 & 32,7 & $-7,4$ & \\
\hline Inconsciente / Desmaio (Quase) & 188 & 43,6 & 243 & 56,4 & 431 & 30,8 & 14,9 & \\
\hline Total & 531 & 38 & 868 & 62 & 1.399 & 100 & 0 & \\
\hline
\end{tabular}

Fonte: Elaboração própria.

Ao analisar as proporções de despacho das queixas mais frequentes nas ocorrências Delta, inferiu-se que a queixa Problemas Respiratórios foi priorizada. As queixas respiratórias tiveram despachos mais frequentes, com uma frequência de despacho de ambulância $14,7 \%$ a mais do que a média das queixas mais frequentes $(\mathrm{p}<0,001)$.

O que é mais importante é a respiração. (MR2).

A inconsciência e a ausência de respiração ou presença de respiração agônica são os sintomas primeiramente investigados, pois indicam ausência de vida. Ao valorizar essas condições, os médicos estão atentos a uma possível não detecção de PCR.

Além de Inconsciência e Problemas Respiratórios, Quedas apresentou destaque na análise dos dados quantitativos e qualitativos. Ela foi uma das queixas mais frequentes no SAMU SP $(8,5 \%)$ e foi priorizada entre Bravo e Alfa. Nestes dois Determinantes, a análise estatística das variáveis despacho e tempo de regulação apresentaram diferenças significativas em relação às outras queixas mais frequentes (Tabelas 2 e 3).

Tabela 2 - Número e porcentagem de ocorrências Bravo (N=3301) e Alfa (N=3619) despachados e não despachados nas queixas principais mais frequentes, SAMU SP. São Paulo, Brasil - out. 2012

\begin{tabular}{|c|c|c|c|c|c|c|c|c|}
\hline \multirow[t]{2}{*}{ Queixa principal } & \multicolumn{2}{|c|}{ Despacho } & \multicolumn{2}{|c|}{$\begin{array}{c}\text { Não } \\
\text { despacho }\end{array}$} & \multicolumn{2}{|c|}{ Total } & \multirow{2}{*}{$\begin{array}{c}\text { Taxa de } \\
\text { variação }\end{array}$} & \multirow[t]{2}{*}{ p-valor } \\
\hline & $\mathbf{n}$ & $\%$ & $\mathbf{n}$ & $\%$ & $\mathbf{n}$ & $\%$ & & \\
\hline Bravo & & & & & & & & $<0,001$ \\
\hline Quedas & 704 & 55,7 & 561 & 44,3 & 1265 & 38,3 & 55,6 & \\
\hline $\begin{array}{l}\text { Psiquiátrico/Comportamento } \\
\text { anormal/Tentativa de suicídio }\end{array}$ & 477 & 23,4 & 1559 & 76,6 & 2036 & 61,7 & $-34,5$ & \\
\hline Total & 1181 & 35,8 & 2120 & 64,2 & 3301 & 100 & $\mathbf{0}$ & \\
\hline Alfa & & & & & & & & $<0,001$ \\
\hline $\begin{array}{l}\text { Pessoa Enferma (Diagnóstico } \\
\text { Específico) }\end{array}$ & 861 & 395 & 1321 & 60,5 & 2182 & 60,3 & $-8,1$ & \\
\hline Quedas & 406 & 53,6 & 352 & 46,4 & 758 & 20,9 & 24,7 & \\
\hline $\begin{array}{l}\text { Dor nas Costas (Não traumática ou } \\
\text { Trauma Não Recente) }\end{array}$ & 287 & 42,3 & 392 & 57,7 & 679 & 18,8 & $-1,6$ & \\
\hline Total & 1554 & 42,9 & 2065 & $\mathbf{5 7 , 1}$ & 3619 & 100 & $\mathbf{0}$ & \\
\hline
\end{tabular}

Fonte: Elaboração própria. 
Tabela 3 - Número e porcentagem de ocorrências Bravo (N=1181) e Alfa (N=1554) despachados com tempo de regulação acima e abaixo de 10 minutos nas queixas principais mais frequentes, SAMU SP. São Paulo, Brasil - out. 2012

\begin{tabular}{|c|c|c|c|c|c|c|c|c|}
\hline \multirow[t]{2}{*}{ Queixa principal } & \multicolumn{2}{|c|}{$\begin{array}{c}\text { TO }<=10 \\
\text { min }\end{array}$} & \multicolumn{2}{|c|}{$\mathrm{TO}>10 \mathrm{~min}$} & \multicolumn{2}{|c|}{ Total } & \multirow{2}{*}{$\begin{array}{c}\text { Taxa de } \\
\text { variação } \\
\% \\
\end{array}$} & \multirow[t]{2}{*}{ p-valor } \\
\hline & $\mathbf{n}$ & $\%$ & $\mathbf{n}$ & $\%$ & $\mathbf{n}$ & $\%$ & & \\
\hline Bravo & & & & & & & & $<0,001$ \\
\hline Quedas & 306 & 43,5 & 398 & 56,5 & 704 & 59,6 & 41,8 & \\
\hline $\begin{array}{l}\text { Psiquiátrico/Comportamento } \\
\text { anormal/Tentativa de suicídio }\end{array}$ & 56 & 11,7 & 421 & 88,3 & 477 & 40,4 & $-61,7$ & \\
\hline Total & 362 & 30,7 & 819 & 69,3 & 1181 & 100 & $\mathbf{0}$ & \\
\hline Alfa & & & & & & & & $<0,001$ \\
\hline $\begin{array}{l}\text { Pessoa Enferma (Diagnóstico } \\
\text { Específico) }\end{array}$ & 225 & 26,1 & 636 & 73,9 & 861 & 55,4 & $-8,1$ & \\
\hline Quedas & 151 & 37,2 & 255 & 62,8 & 406 & 26,1 & 30,8 & \\
\hline $\begin{array}{l}\text { Dor nas Costas (Não traumática ou } \\
\text { Trauma Não Recente) }\end{array}$ & 66 & 23 & 221 & 77 & 287 & 18,5 & $-19,1$ & \\
\hline Total & 442 & 28,4 & 1112 & 71,6 & 1554 & 100 & $\mathbf{0}$ & \\
\hline
\end{tabular}

Fonte: Elaboração própria

Uma queda pode ter sido resultado de algum agravo clínico ou do processo de envelhecimento, fazendo com que os médicos valorizem as ocorrências cuja queixa principal seja esta.

70 anos que caiu no banheiro, não dá para deixar ele como Alfa, né? Independente do que a pessoa respondeu na entrevista [...] uma queda no idoso é sempre grave. (MR1).

\section{Condições de riscos específicos}

Os médicos reguladores consideravam um outro grupo de critérios de vulnerabilidade e risco específicos associados à ocorrência no processo de priorização de despachos que incluíam principalmente questões de idade, violência, aglomeração populacional, necessidades locais do território onde a ligação é feita e a interação com outros serviços. A idade do paciente é um critério demográfico levado em consideração na avaliação das ocorrências, sendo priorizadas as crianças e os idosos.

Qualquer doente abaixo de 3 anos ou acima de 70 anos a gente já tem que se preocupar; são os extremos de idade que existe uma labilidade clinica muito grande. (MR1).

A necessidade de intervenção terapêutica ou de procedimentos diagnósticos era levada em consideração pelos médicos. As entrevistas indicaram que pacientes classificados de baixa prioridade, apesar de não apresentarem risco de morte, se beneficiariam do atendimento pré-hospitalar.

É um acidente [...] ou caiu e está sangrando muito, e aí você pode pensar que pode ser uma fratura exposta, aí você já prioriza também, porque às vezes, quando eles vão colocar no protocolo, ele não entra numa prioridade alta. Então, isso, a gente tem que ter o cuidado. (MR2).

Esta postura dos médicos é confirmada pela análise estatística, quando se constata que, dentre os casos que efetivamente chegaram ao local da ocorrência, as maiores porcentagens de transporte para o hospital encontravam-se nos Determinantes de baixa prioridade (variação entre 35,6\% nos Echo a 84,0\% nos Ômega), mesmo que com tempos de regulação maiores.

A preocupação com sintomas de gravidade clínica faz com que queixas menores do ponto de vista clínico, mesmo que em sofrimento, permaneçam na fila de espera de despacho. Este é o caso das ocorrências psiquiátricas.

Sempre tem casos mais graves, que implica em risco de morte. Psiquiátrico é grave, chateia, é um drama, mas não tem risco de morte. Então, ele sempre é protelado. (MR1).

Quase todas as queixas psiquiátricas foram classificadas como Bravo e Alfa (96,7\%). Segundo os entrevistados, as ocorrências relacionadas à Saúde Mental eram priorizadas apenas 
quando havia risco de morte do paciente ou quando havia a presença de violência e vulnerabilidade de terceiros, com a presença da Polícia Militar.

Psiquiátricos precisam do SAMU desde que envolva risco de vida. (MR2).

Casos de psiquiatria são atendidos nessas condições: violência, começou a quebrar as coisas; por algum motivo a família acionou a polícia e a polícia restringiu. (MR1).

A queixa denominada "Solicitação de Numeral" diz respeito às ocorrências acionadas pelos serviços de segurança pública, como Polícia ou Corpo de Bombeiros. Essas corresponderam a 4,0\% (1.508) da demanda, sendo a $10^{\mathrm{a}}$ queixa mais frequente. Quando esses serviços solicitam a presença do SAMU, essas ocorrências são priorizadas e automaticamente classificadas como Delta. No período analisado foram despachadas em $97,9 \%$ dos casos.

\section{Condições intrinsecas ao SAMU}

A restrição de recursos do SAMU também influenciou no processo de priorização das ocorrências. Devido ao fato de não haver recursos suficientes, os médicos levavam em consideração o tempo de espera e o número de reiterações realizadas pelos solicitantes. Eles consideravam que, durante esse tempo, a condição clínica do paciente podia ter deteriorado, sendo necessário a priorização da ocorrência.

\begin{abstract}
A primeira coisa que eu faço é ver quem reiterou mais vezes [...] eu, particularmente, não negligencio nenbuma reiteração. A pessoa liga, tem muita gente que liga para tirar um peso da consciência, mas quando a pessoa liga de novo, alguma coisa tem. Então, como eu te falei, pela falta de material bumano aqui na regulação, eu vou valorizando o maior número de reiteração. (MR1).
\end{abstract}

É dificil a gente ficar ligando para todo mundo, a não ser algum caso que você vê que está lá embaixo que está muitas horas esperando, porque ele não é uma prioridade máxima, assim, de estar enviando um recurso rápido. Então a gente liga. (MR2).

Às vezes a gente até leva em conta o tempo. Está demorando, sei lá, tem um chamado lá Delta há meia hora e tem outro que chegou agora. Então você vai ver primeiro esse de trinta minutos o que é, para ver se esse que chegou agora é mais grave ou menos grave do que aquele de trinta minutos que está esperando. (MR3).

Os informantes-chave relataram contar com a colaboração dos diversos profissionais na central, como despachadores, TARM e enfermeiros, que, com sua experiência no serviço, chamavam a atenção para alguns casos específicos que se beneficiariam de uma avaliação médica telefônica.

\footnotetext{
Eles [TARM] ajudam muito [...] eles vão abrindo; às vezes eles chamam atenção "ob doutor, tem um caso assim, assim e assim, quer dar uma olhada?" Ai a gente liga para o paciente e decide. Muitas vezes eles têm razão. (MR1).

Às vezes eles [TARM] têm dúvida de alguma coisa e então eles conversam com a gente. Então existe esse diálogo, essa troca. (MR2).
}

Esse trabalho colaborativo influencia no processo de priorização, facilitando o trabalho dos médicos reguladores, que têm a função de garantir o acesso à assistência pré-hospitalar a pacientes que necessitam desse nível de assistência. Num cenário de poucos recursos, sejam materiais (ambulâncias), sejam humanos (médicos), a atuação dos reguladores torna-se ainda mais importante, uma vez que serve de rede de segurança para o sistema.

\section{Discussão}

Os dados qualitativos da pesquisa revelaram que o SAMU SP, ao utilizar o MPDS, fortalecia a cadeia de sobrevivência, despachava rapidamente a ambulância, e iniciava instruções de ressuscitação cardiopulmonar para casos de PCR. Diversos estudos demonstram a eficiência do MPDS na detecção de PCR ${ }^{(21-25)}$.

O protocolo utilizado garante que, diante de uma demanda volumosa, seja possível detectar e responder rapidamente a esse tipo de solicitação. Ele evita que haja uma fila de espera sem uma classificação adequada, como observado no Rio de Janeiro ${ }^{(26)}$. A utilização de outros níveis de gravidade definidos pelos Determinantes do software auxilia o processo de decisão do despacho de ambulância, mas apresenta distintos tempos de resposta.

A demanda habitualmente represada no SAMU fica em fila de espera, porém já ordenada pela classificação de prioridade dada pelo MPDS. Esta classificação auxilia o processo de trabalho do médico regulador que atua como uma rede 
de segurança, pois somente ele possui a autoridade sanitária de incluir o paciente na RAU ou de considerar desnecessário o envio de recursos. Ele realiza o ajuste fino da priorização, corrigindo deficiências do protocolo, adaptando as situações à realidade local e à situação do momento, baseado nos recursos disponíveis (ambulâncias e profissionais de apoio na Central de Regulação) ${ }^{(27)}$.

As condições clinicas reportadas mostram que problemas Respiratórios é a queixa principal mais frequente entre os serviços de APH que utilizam o MPDS e correspondem a uma variedade de condições ${ }^{(22)}$. Estudos apontam dificuldades por parte dos despachadores e dos solicitantes em avaliar dificuldade respiratória ${ }^{(24,28,33)}$. Esses dois fatos justificam a atenção dada pelos médicos a esse sintoma. Outra condição clínica reportada é queda, tanto na análise do banco de dados como nas falas dos entrevistados. Esta queixa, aparentemente pouco específica, apresentou, em um estudo, um número elevado de diagnóstico com PCR após a ambulância chegar ao local ${ }^{(29)}$. A queda pode ter sido resultado de alguma condição clínica subjacente, como síncope causada por IAM ou doenças vasculares cerebrais. Esse estudo ressalta a importância de perguntas relativas à respiração e à consciência nos protocolos de Quedas ${ }^{(29)}$. A priorização de quedas com valorização de queixas clínicas e sinais de morte é de extrema importância, como descrito pelos entrevistados.

Nas condições de risco específico, a priorização dos médicos pelas ocorrências de baixa prioridade permite a atenção a casos de menor risco de vida, mas com outras necessidades. Apesar de estudos demonstrarem que o MPDS é seguro para pacientes com baixa gravidade clínica $^{(34)}$, a maioria dos APH que o utilizam é capaz de despachar para a totalidade dos casos, inclusive os de baixa prioridade. Portanto, a avaliação do regulador torna-se ainda mais importante no contexto do SAMU SP, garantindo a segurança do paciente. Necessidade de intervenções hospitalares ou procedimentos diagnósticos, extremos de idade e a interação com serviços de segurança pública são fatores que levam os reguladores a despachar recurso para ocorrências de baixa prioridade.

A priorização dos casos de Saúde Mental apenas quando se identifica a presença de risco de morte e violência indica que a atuação do SAMU visa a preservação da vida e o controle dos $\operatorname{corpos}^{(35)}$. Em relação a esta queixa foram identificados distintos procedimentos do SAMU. Assim, em Tocantins, por exemplo, houve predominância dos pacientes agitados dentre as ocorrências de natureza psiquiátrica ${ }^{(15)}$. No SAMU de Sobral, profissionais relataram o apoio policial como um dos facilitadores no atendimento, quando a agressividade estava presente ${ }^{(35)}$. No SAMU SP, a solicitação de despacho pela Polícia Militar e Corpo de Bombeiros é atendida prioritariamente.

Segundo os entrevistados e a observação direta realizada, as condições intrínsecas ao processo de trabalho dentro da Central de Operações do SAMU SP também influenciavam no processo de priorização das ocorrências. Os médicos reguladores deparavam-se com uma demanda alta, onde a avaliação médica da totalidade das ocorrências era dificultada. O processo de trabalho era organizado em torno da necessidade de priorização, e o médico regulador, além de contar com a pré-triagem realizada pelo uso do protocolo MPDS, contava com o trabalho cooperativo de despachadores, TARM e enfermeiros. Estes sinalizavam ocorrências que necessitavam de maior atenção, induzindo, assim, a priorização de certos casos. A atuação dos despachadores nas ocorrências Echo, assim como as ações de enfermeiros nas ocorrências de baixa prioridade, auxiliava o processo decisório do médico regulador, indicando que havia compartilhamento da responsabilidade do processo de despacho de ambulância com a equipe da central de regulação.

No caso em estudo, diante de um cenário de poucos recursos, a atuação dos médicos reguladores no processo de priorização visava adequar a demanda à oferta disponível. Enquanto a classificação de prioridade era realizada de maneira prescritiva/objetiva por meio do protocolo MPDS, a avaliação médica era realizada de forma mais 
aprofundada e qualificada, tendo como base os conhecimentos técnico-científicos do médico regulador, assim como a situação da fila de espera e a disponibilidade de ambulâncias. O médico regulador, com o auxílio de outros profissionais da Central, realizava o ajuste fino do processo de priorização e despacho de ambulância, visando corrigir possíveis falhas do protocolo, adaptando as situações à realidade local e à situação do momento.

\section{Conclusão}

Esta pesquisa permitiu compreender o alcance do SAMU SP como uma porta de entrada para a RAU. O médico regulador despacha ambulâncias para casos com risco de morte, prioriza casos com deterioração clínica (inconsciência, problemas respiratórios e quedas), com necessidade de transporte para hospital, com vulnerabilidades associadas à idade e aos casos de violência, e atende prioritariamente demandas dos serviços de segurança pública.

Este ajuste fino consiste no processo decisório do médico regulador, que é influenciado pelos fatores discutidos nesta pesquisa. Fica evidente que as condições clínicas e a vulnerabilidade e o risco das ocorrências de emergência determinam o tipo e o tempo de resposta que o SAMU oferece aos usuários. Diante do cenário de alta demanda, os recursos disponíveis são direcionados de maneira mais ágil aos pacientes que mais precisam do ponto de vista biomédico, tendo em vista principalmente a parada cardiorrespiratória.

Os resultados deste estudo podem subsidiar a organização do processo de trabalho das Centrais de Regulação dos SAMU, promovendo o debate sobre a maneira pela qual o SAMU oferece acesso ao sistema de saúde e insere-se na Rede de Atenção às Urgências. Ao identificar os critérios de acesso ao SAMU, é possível contribuir para a conformação da RAU e a articulação desse serviço com a rede de atenção à saúde dos municípios e regiões de saúde, principalmente no que diz respeito à demanda não absorvida pelo serviço.

\section{Colaborações:}

1. concepção, projeto, análise e interpretação dos dados: Flavia Saraiva Leão Fernandes e Oswaldo Yoshimi Tanaka;

2. redação do artigo e revisão crítica relevante do conteúdo intelectual: Flavia Saraiva Leão Fernandes e Oswaldo Yoshimi Tanaka;

3. aprovação final da versão a ser publicada: Oswaldo Yoshimi Tanaka.

\section{Referências}

1. Shah MN. The formation of the emergency medical services system. Am J Public Health. 2006;96(3):414-23.

2. Ramos VO, Sanna MC. A inserção da enfermeria no atendimento pré-hospitalar: histórico e perspectivas atuais. Rev Bras Enferm. 2005;58(3):355-60.

3. Tannebaum RD, Arnold JL, De Negri Filho A, Spadoni VS. Emergency medicine in Southern Brazil. Ann Emerg Med. 2001;37(2):223-8.

4. Machado CV, Salvador FGF, O’Dwyer G. Serviço de Atendimento Móvel de Urgência: análise da política brasileira. Rev Saúde Pública. 2011;45(3):519-28.

5. Lopes SLB, dos Santos JS, Scarpelini S. The implementation of the Medical Regulation Office and Mobile Emergency Attendance System and its impact on the gravity profile of non-traumatic afflictions treated in a University Hospital: a research study. BMC Health Serv Res. 2007 Oct $24 ; 7: 7-173$.

6. Minayo MCD, Deslandes SF. Análise da implantação do sistema de atendimento pré-hospitalar móvel em cinco capitais brasileiras. Cad Saúde Pública. 2008;24(8):1877-86.

7. O’Dwyer G, Machado CV, Alves RP, Salvador FG. Atenção pré-hospitalar móvel às urgências: análise de implantação no estado do Rio de Janeiro, Brasil. Ciênc Saúde Colet. 2016 jul;21(7):2189-200.

8. Teles AS, Coelho TCB, Ferreira MPS, Scatena JHG. Serviço de Atendimento Móvel de Urgência (SAMU) do Estado da Bahia: subfinanciamento e desigualdade regional. Cad Saúde Colet. 2017;25(1):51-7.

9. Ortiga AM, Lacerda JT, Natal S, Calvo MC. Avaliação do Serviço de Atendimento Móvel de 
Urgência em Santa Catarina, Brasil. Cad Saúde Pública. 2016;32(12):e00176714.

10. Cabral A, Souza W. Serviço de Atendimento Móvel de Urgência (SAMU): análise da demanda e sua distribuição espacial em uma cidade do Nordeste brasileiro. Rev Bras Epidemiol. 2008;11(4):530-40.

11. Gonsaga RAT, Silva EM, Brugugnoli ID, Cabral JL, Thomé Neto O. Padrão e necessidades de atendimento pré-hospitalar a idosos. Rev Bras Geriatr Gerontol. 2015;18(1):19-28.

12. Silva N, Nogueira L. Avaliação de indicadores operacionais de um serviço de atendimento móvel de urgência. Cogitare Enferm. 2012 jul/ set;17(3):471-7.

13. Dantas R, Costa I, Nóbrega W, Dantas D, Costa I, Torres G. Ocorrências realizadas pelo Serviço de Atendimento Móvel de Urgência metropolitano. Rev enferm UFPE on line. 2014 [cited 2016 Aug 2];8(4):842-9. Available from: https://periodicos. ufpe.br/revistas/revistaenfermagem/article/ viewFile/10102/10568

14. Gonsaga R, Brugugnolli I, Zanutto T, Gilioli J, Silva L, Fraga G. Características dos atendimentos realizados pelo Serviço de Atendimento Móvel de Urgência no município de Catanduva, Estado de São Paulo, Brasil, 2006 a 2012. Epidemiol Serv Saúde. 2013;22(2):317-24.

15. Pitteri J, Monteiro P. Caracterização do Serviço de Atendimento Móvel de Urgência (SAMU) em Palmas-Tocantins, Brasil, em 2009. Comun ciênc saúde. 2010;21(3):227-36.

16. Deslandes SF, Minayo MCS, Lima MLC. Atendimento de emergência às vítimas de acidentes e violências no Brasil. Rev Panam Salud Publica. 2008;24(6):430-40.

17. Ciconet R. Tempo resposta de um serviço de atendimento móvel de urgência (tese). Porto Alegre: Escola de Enfermagem, Universidade Federal do Rio Grande do Sul; 2015.

18. Creswell J. A concise introduction to Mixed Methods Research. Thousand Oaks (CA): SAGE Publications; 2015.

19. O'Cathain A, Murphy E, Nicholl J. Integration and publications as indicators of "Yield" from mixed methods studies. J Mix Methods Res. 2007;1(2):147-63.

20. Bardin L. Análise de conteúdo. 6a ed. Lisboa: Edições 70; 2011.
21. Clawson J, Olola C, Scott G, Schultz B, Pertgen R, Robinson D, et al. Association between patient unconscious or not alert conditions and cardiac arrest or high-acuity outcomes within the Medical Priority Dispatch System "Falls" protocol. Prehosp Disaster Med. 2010 Jul-Aug;25(4):302-8.

22. Heward A, Damiani M, Hartley-Sharpe C. Does the use of the Advanced Medical Priority Dispatch System affect cardiac arrest detection? Emerg Med J. 2004 Jan;21(1):115-8.

23. Feldman MJ, Verbeek PR, Lyons DG, Chad SJ, Craig AM, Schwartz B. Comparison of the medical priority dispatch system to an out-of-hospital patient acuity score. Acad Emerg Med. 2006;13(9):954-60.

24. Berdowski J, Beekhuis F, Zwinderman AH, Tijssen JG, Koster RW. Importance of the first link: description and recognition of an out-of-hospital cardiac arrest in an emergency call. Circulation. 2009;119(15):2096-102.

25. Hardeland C, Olasveengen TM, Lawrence R, Garrison D, Lorem T, Farstad G, et al. Comparison of Medical Priority Dispatch (MPD) and Criteria Based Dispatch (CBD) relating to cardiac arrest calls. Resuscitation. 2014;85(5):612-6.

26. O’Dwyer G, Mattos RA. Cuidado integral e atenção às urgências: o serviço de atendimento móvel de urgência do estado do Rio de Janeiro. Saúde Soc. 2013;22(1):199-210.

27. O'Dwyer G, Mattos R. O SAMU, a regulação no Estado do Rio de Janeiro e a integralidade segundo gestores dos três níveis de governo. Physis. 2012;22(1):141-60.

28. Clawson J, Olola C, Heward A, Patterson B, Scott G. Profile of emergency medical dispatch calls for breathing problems within the medical priority dispatch system protocol. Prehosp Disaster Med. 2008;23(5):412-9.

29. Clawson J, Barron T, Scott G, Siriwardena AN, Patterson B, Olola C. Medical Priority Dispatch System breathing problems protocol key question combinations are associated with patient acuity. Prehosp Disaster Med. 2012;27(4):375-80.

30. Bång A, Herlitz J, Martinell S. Interaction between emergency medical dispatcher and caller in suspected out-of-hospital cardiac arrest calls with focus on agonal breathing. A review of 100 tape recordings of true cardiac arrest cases. Resuscitation. 2003;56(1):25-34.

31. Nurmi J, Pettilä V, Biber B, Kuisma M, Komulainen R, Castrén M. Effect of protocol compliance to 
cardiac arrest identification by emergency medical dispatchers. Resuscitation. 2006;70(3):463-9.

32. Hauff SR, Rea TD, Culley LL, Kerry F, Becker L, Eisenberg MS. Factors impeding dispatcher-assisted telephone cardiopulmonary resuscitation. Ann Emerg Med. 2003;42(6):731-7.

33. Vaillancourt C, Charette ML, Bohm K, Dunford J, Castrén M. In out-of-hospital cardiac arrest patients, does the description of any specific symptoms to the emergency medical dispatcher improve the accuracy of the diagnosis of cardiac arrest: A systematic review of the literature. Resuscitation. 2011;82(12):1483-9.
34. Garza AG, Gratton MC, McElroy J, Lindholm D, Glass E. The association of dispatch prioritization and patient acuity. Prehosp Emerg Care. 2008;12(1):24-9.

35. Dias L, Vasconcelos M, Vasconcelos A, Moraes K. Atendimento pré-hospitalar às urgências psiquiátricas por uso de substâncias psicoativas. SANARE. 2013;12(2):47-53.

Recebido: 18 de outubro de 2017

Aprovado: 12 de março de 2018

Publicado: 23 de maio de 2018

A Revista Baiana de Enfermagem utiliza a Licença Creative Commons - Atribuição-NãoComercial 4.0 Internacional.

https://creativecommons.org/licenses/by-nc/4.0/

Este artigo é de acesso aberto distribuído sob os termos da Licença Creative Commons (CC BY-NC).

Esta licença permite que outros remixem, adaptem e criem a partir do seu trabalho para fins não comerciais e, embora, os novos trabalhos tenham de lhe atribuir o devido crédito e não possam ser usados para fins comerciais, os usuários não têm de licenciar esses trabalhos derivados sob os mesmos termos. 